\title{
INFECTIVITY OF Oryctes NUDIVIRUS PRODUCED ON CELL CULTURE DSIR HA-1179 AGAINST LARVAE AND ITS EFFECTS ON FEEDING OF NEONATES OF RHINOCEROS BEETLE, Oryctes rhinoceros
}

\section{NUR AIN FARHAH ROS SAIDON KHUDRI*; WAHIZATUL AFZAN AZMI*; RAMLE MOSLIM**; NORMAN KAMARUDIN** and SITI RAMLAH AHMAD ALI**}

\begin{abstract}
The Oryctes nudivirus (OrNV) is a classical biocontrol agent for a major oil palm insect pest the rhinoceros beetle, Oryctes rhinoceros. The infectivity of three Malaysian indigenous types of OrNV types A, B and $C$ were tested on larvae and neonates. On larvae, the peroral inoculation test technique indicated that the highest mortality of 100\% was achieved using type A produced from cell culture DSIR-HA-1179, while the highest infectivity of $41.7 \%$ was recorded for type A prepared from infected guts. No differences in infectivity were observed on other treatments, which ranged from $13.1 \%$ to $41.7 \%$. In the substrate contamination inoculation test technique, results showed that the level of infectivity was even lower in all OrNV treatments, ranging as low as $6.7 \%$ to only $15.0 \%$. Low infectivity was mainly due to inactivation of virus inocula in the larval food substrates. Based on the results for both inoculation methods, the OrNV type C prepared from cell culture DSIR-HA-1179 was found more effective in controlling the L3 larvae than the other types of OrNV. The impact of OrNV infection on food consumption by the neonates was studied. The feeding of inoculated neonates with OrNV reduced rapidly, especially at the early stage of the experiment between eight days after treatment (DAT) to 16 DAT. At this period, the food consumption by all tested OrNV was rapidly reduced and maintained low until the experiment ended at 60 DAT. The highest feeding reduction rate was on neonates treated by type $A(-0.074 x)$ followed by neonates treated by type $C(-0.053 x)$ and type B (-0.035x). Therefore, it was suggested that besides on highly virulent, the selection of OrNV for field release should also based on high reduction rate on food consumption by the infected insects on plant hosts.
\end{abstract}

Keywords: Oryctes rhinoceros, Oryctes nudivirus, oil palm insect pest, food consumption.

Date received: 19 April 2016; Sent for revision: 20 April 2016; Received in final form: 27 July 2016; Accepted: 28 July 2016.

\section{INTRODUCTION}

School of Marine and Environmental Sciences,

Universiti Malaysia Terengganu, T145,

21030 Kuala Terengganu, Terengganu, Malaysia.

** Malaysian Palm Oil Board,

6 Persiaran Institusi Bandar Baru Bangi, 43000 Kajang,

Selangor, Malaysia.

E-mail: ramle@mpob gov.my
The outbreaks of economically important pests, such as the rhinoceros beetle, Oryctes rhinoceros have greatly affected the sustainability of the oil palm development in Malaysia. Reasons that contribute to the outbreak are highly associated with the abundance of breeding sites due to prohibition of open burning in the plantations during the early stage of land preparation (Bedford, 2013a). The 
attacks of rhinoceros beetle on oil palm occurred in both mature and immature areas (Norman and Basri, 2004). However, the attack is more lethal to the young growing palm below 4 years old (Cik Mohd Rizuan et al., 2014).

Feeding activity by the adults causes the formation of wedged-shaped leaves when the young fronds unfold and this affects the yield of the palm (Samsudin et al., 1993). The entry feeding holes left by the rhinoceros beetles could attract a secondary pest such as Rhynchophorus ferrugineus (Wood, 1968). The photosynthetic areas of the severely attacked palm can be reduced up to $15 \%$, thus, delaying the palm maturity as well as reducing the yield of the palm (Samsudin et al., 1993). Chung et al. (1999) estimated that losses due to the infestation of beetles on 21-month old palm has lowered the production of fresh fruit bunches (FFB) to almost $80 \%$ in the first year after attack.

The arthropod-specific entomopathogen virus, the Oryctes nudivirus (OrNV) is one of the natural enemies to hamper the beetle populations in the plantations. The virus was isolated from larvae in Malaysia (Huger, 1966), and has been proven to be lethal to larvae and adults of rhinoceros beetles (Huger, 2005). Larvae get infected via feeding on the virus contaminated substrates, while infection on adults was mostly via mating (Zelazny and Alfiler, 1991). The adults were found acting as a virus reservoir, transmitting the virus within the population. The virus then replicated in the gut tissues, thus reducing the feeding activity as well as the fertility of females (Zelazny, 1973). Following a successful pilot release in Samoa, which significantly reduced the beetle population, the OrNV was then introduced in many South Pacific and Indian Ocean countries (Marschall, 1970; Zelazny and Alfiler, 1991). In Fiji, the impact of OrNV helped to suppress and maintained the beetle population below the economic threshold level even up to 40 years after the introduction (Bedford, 2013b).

The cell line DSIR-HA-1179 was established from the African black beetle Heteronychus arator (Crawford, 1982) and it was the only cell line that supports the in vitro propagation of the OrNV (Crawford and Sheehan, 1985). As this technology enables the production of OrNV with high purity, it has been widely used by various researchers to release the OrNV to control rhinoceros beetles in both coconut and oil palm plantations (Crawford and Sheehan, 1984; Zelazny et al., 1987). Our previous study showed that the Malaysian OrNV types A, B, and C have been successfully produced on insect cell line DSIR-HA-1179 and all OrNV inocula were proven highly pathogenic on adults rhinoceros beetle.

This research further evaluated the infectivity of the cell-propagated OrNV and the wild-collected OrNV on the larvae of the rhinoceros beetles using peroral and substrate contamination inoculation methods. The feeding behaviours of neonates of rhinoceros beetle inoculated with the OrNV were also studied.

\section{MATERIALS AND METHODS}

\section{Source of OrNV Solution}

All the three OrNV solutions, types A, B and $C$ were prepared from two weeks old insect cell line DSIR-HA-1179, provided by the AgResearch, New Zealand. The cells were grown in a $25 \mathrm{~cm}^{2}$ flask with $5 \mathrm{ml}$ PS100 medium containing 10\% fetal bovine serum (FBS) and antibiotics. Propagation of all types of OrNV in cell cultures was performed following the method of Farhah et al. (2015). The initial seeding density used in each flask was at $1 \times 10^{5}$ viable cells $/ \mathrm{ml}$. A total of $100 \mu \mathrm{l}$ of OrNV solution prepared from homogenated infected gut tissues of adults of rhinoceros beetle from respective localities were added into the cell culture. The OrNV type A solution was prepared from the infected guts of adults collected from Munkar Estate in Johor, Malaysia, type B from Seberang Perak Estate in Perak, Malaysia and type C from Lahad Datu, Sabah, Malaysia. Prior to inoculation, the respective OrNV solutions were purified by double filtration through; first a $0.45 \mu \mathrm{m}$, and second a 0.22 $\mu \mathrm{m}$ membrane filter to avoid the presence of other microorganisms.

\section{Source of Larvae and Neonates}

The third instar larvae (L3) were collected from breeding sites at Regent Estate, IOI in Melaka, Malaysia. The L3 larvae were determined by measuring the diameter of the head capsules with an average of $9.1 \mathrm{~mm}$ (Norman, 2001). Larvae with any signs of viral or fungal infection were discarded and only the healthy larvae were picked up and placed into a plastic container with dimension of 60 $\mathrm{cm}$ long $\times 45 \mathrm{~cm}$ wide $\times 30 \mathrm{~cm}$ high, half filled with rotting chipped palm trunks. The collected larvae were brought back to an outdoor insectory for rearing. The larvae were then kept individually in a $500 \mathrm{ml}$ plastic cup filled with moist rotting chipped oil palm trunks. The temperature of the insectory was maintained at $25^{\circ} \mathrm{C}$ to $28^{\circ} \mathrm{C}$. The food source in each cup was replaced every two weeks until the larvae turned to neonates.

\section{DNA Extraction for PCR Analysis}

The DNA of OrNV was extracted from the infected gut of both larvae and adults following the protocol as described by Ramle et al. (2010). The gut tissues were macerated and then briefly 
centrifuged to pellet the gut tissues. A total of 150 $\mu 1$ of solution were transferred into a new $1.5 \mathrm{ml}$ microtube. A volume of $300 \mu 1$ disruption buffer containing $50 \mu \mathrm{l} 1 \mathrm{M}$ Tris pH8, $10 \mu \mathrm{l} 0.5 \mathrm{M}$ EDTA, $5 \mu \mathrm{l}$ $10 \%$ SDS, $2.5 \mu \mathrm{l}$ proteinase $\mathrm{K}\left(20 \mathrm{mg} \mathrm{ml}^{-1}\right)$, and 232.5 $\mu \mathrm{l}$ sterilised millique water $\left(\mathrm{SMqH}_{2} \mathrm{O}\right)$ was added into the tube. The mixture was then shaken and incubated at $65^{\circ} \mathrm{C}$ for $60 \mathrm{~min}$. Then, equal amount of phenol-chloroform-isoamylalcohol (PCI) (25:24:1) was added into the microtube. The mixture solution was mixed by inversion for several times. After centrifugation for $10 \mathrm{~min}$ at $13000 \mathrm{rpm}, 450 \mu \mathrm{l}$ of the upper solution were pipetted and transferred into new microtube. Precipitation of OrNV DNA was then conducted by filling $10 \% \mathrm{NaAc} \mathrm{pH} 5.2$ and two times volume of $100 \%$ ethanol into the microtube. The mixture was then kept at $-20^{\circ} \mathrm{C}$ for an hour. The OrNV DNA was pelletised by centrifugation at $13000 \mathrm{rpm}$ for $10 \mathrm{~min}$, then rinsed twice by adding $100 \%$ alcohol, air-dried and finally suspended in 100 $\mu 1$ TE buffer.

\section{Polymerase Chain Reaction (PCR) Analysis for Detection of OrNV}

The PCR analysis conducted in this study followed the optimised techniques by Ramle et al. (2010), using a pair of primers $15 \mathrm{a}\left(5^{\prime}\right.$ - ATT ACT TCG TAG AGG CAA TC - 3') and 15b (5' - CAT GAT CGA TTC GTC TGT GG - 3') developed by Richards et al. (1999). The PCR was carried out in $0.2 \mathrm{ml}$ microtube by mixing $4.0 \mu \mathrm{l}$ of OrNV DNA and 22.0 $\mu \mathrm{l}$ lysis buffer containing $14.63 \mu \mathrm{l}$ of $\mathrm{SMqH}_{2} \mathrm{O}, 1.25$ $\mu \mathrm{l}$ of $\mathrm{MgCl}_{2}, 2.5 \mu \mathrm{l}$ of 10X PCR buffer $10 \mathrm{mM}, 0.5 \mu \mathrm{l}$ DNTP, $1 \mu \mathrm{l}$ of each primer $15 \mathrm{a}$ and $15 \mathrm{~b}, 0.125 \mu \mathrm{l}$ Taq DNA polymerase, and $1 \mu \mathrm{l}$ bovine serum albumin (BSA) $\left(20 \mathrm{mg} \mathrm{ml}^{-1}\right)$. The addition of BSA was used to improve the yields of DNA in the PCR (Farell and Alexandre, 2012). Samples used for positive and negative control were included in each reaction. Sample for positive control used the previously confirmed OrNV DNA, whereas sample for the negative control used only the $\mathrm{SMqH}_{2} \mathrm{O}$. The PCR was performed in a thermal cycler machine (Vapo Protect, Eppendorf) run for 30 cycles; denaturing at $94^{\circ} \mathrm{C}$ for $1 \mathrm{~min}$, annealing at $72^{\circ} \mathrm{C}$ for $2 \mathrm{~min}$ and extension at $50^{\circ} \mathrm{C}$ for $1 \mathrm{~min}$. The PCR products were electrophoresed on $1.8 \%$ agarose gel prepared using 1X TAE buffer with ethidium bromide. The gel was then visualised under the UV transillumination. The presence of single DNA band at $945 \mathrm{bp}$ confirmed that the sample was infected by OrNV.

Experiment 1: Infectivity of cells-propagated and field-collected OrNV on larvae tested by peroral inoculation technique. Three types (type A, B, and C) of OrNV from two different preparations of inoculum were tested against the early stage of L3 larvae of rhinoceros beetle. First inoculum of OrNV was prepared from two weeks old insect cell culture produced following the method of Farhah et al. (2015). The second inoculum was prepared from the infected gut tissues of adults collected from estates in Johor for type A, in Perak for type B, and in Sabah for type C. The study was carried out in a randomised complete block design (RCBD) with three replicates for each treatment. The number of tested larvae in each replicate was five larvae, accounting for a total of 105 larvae (90 larvae used in treatments and 15 larvae in control). Larvae were collected from the same locality and maintained as previously described. Prior to bioassay, the infection level of OrNV on larvae was estimated using PCR analysis from $10 \%$ of total larvae used in the study. The PCR results showed that the samples of larvae were free from OrNV infection.

Prior to inoculation of larvae, the concentrations of each type of OrNV prepared from both inocula were estimated by PCR-comparative method and then standardised at $1-2 \times 10^{4}$ infectious unit (IU) $\mathrm{ml}^{-1}$ in $10 \%$ sucrose solution. Inoculation of larvae was conducted peroral by placing $30 \mu \mathrm{l}$ of OrNV solution onto the mouthparts of the larvae. A group of five inoculated larvae were placed in a plastic container with dimension of $11 \mathrm{~cm}$ width $\times 17 \mathrm{~cm}$ length $\times 7.5 \mathrm{~cm}$ height, filled with chipped rotten oil palm trunks as food source. For control, the larvae were only inoculated with $30 \mu 1$ of $10 \%$ sucrose solution. Mortality of the larvae was recorded every four days after treatment (DAT) until one of the treatments achieved $100 \%$ mortality. The dead larvae were dissected and the midgut tissues were taken for confirmation of OrNV infection using the PCR method as described above.

Experiment 2. Infectivity of cells-propagated OrNV on larvae tested using substrate contamination inoculation technique. This experiment only tested OrNV types A, B, and C propagated on cell culture DSIR-HA-1179 against the late stage L3 larvae using substrate contamination inoculation technique. The age of larvae was about 30 days older than the larvae used in Experiment 1. The preparation and standardisation of OrNV inocula were conducted as in Experiment 1. A total of $10 \mathrm{ml}$ of OrNV solutions prepared in $10 \%$ sucrose were directly sprayed onto the larval breeding substrates which comprised of chipped rotten oil palm trunks in a container. Before adding a group of five larvae into the container, the substrates were homogenously mixed. In control, the breeding substrates were left uninoculated. The containers were then placed in dark condition at $25^{\circ} \mathrm{C}$ to $28^{\circ} \mathrm{C}$ to minimise the effects of biotic factors in degrading the OrNV inocula. The mortality of larvae was inspected every four DAT, until one of the treatments reached $100 \%$ mortality. All the dead larvae were subjected to PCR analysis to confirm the OrNV infection. 
Experiment 3. Effects of OrNV infectivity on feeding behaviour of neonates of rhinoceros beetle. The OrNV types A, B, and C propagated from cell culture were used in this study (Farhah et al., 2015). The concentration of each types of OrNV was set at $1-2 \times 10^{4} \mathrm{IU} \mathrm{ml}^{-1}$. The study was carried out in a RCBD with five replicates per treatment, consisted of five neonates for every replicate. Neonates of rhinoceros beetle were obtained from rearing of L3 larvae as previously described. A day before the administration of OrNV inocula, the neonates were placed inside an empty container for fasting overnight, as this will facilitate the inoculation of OrNV to neonates (Ramle et al., 2011). Administration of OrNV was conducted by placing $30 \mathrm{ul}$ of virus inoculum onto the mouthparts of the neonates (Ramle et al., 2011). The inoculated neonates were kept in a transparent plastic container and fed with several pieces of sugar-cane of about $20 \mathrm{~cm}$ long. The infectivity of OrNV and food consumption of neonates was recorded every four days until 60 DAT. All the dead neonates were subjected to PCR analysis to confirm the OrNV infection following the method of Ramle et al. (2010).

\section{Statistical Analysis}

The cumulative percentage of mortality and infection was firstly corrected using the Abbott's Formula (Abbott, 1987) then angularly transformed before analysis of ANOVA was performed. The means were separated using Duncan's Multiple Range Test at $\mathrm{P}=0.05$ (SAS, 1997). The mean of food consumption was subjected to ANOVA (SAS, 1997). The rates of food consumption over time were plotted using a negative exponential curve graphs by SigmaPlot 10.0 .

\section{RESULTS AND DISCUSSION}

Infectivity of Cells-propagated and Field-collected OrNV on Larvae Tested by Peroral Inoculation Technique

All types of OrNV prepared from both inocula, cell culture or gut tissues, were capable to cause mortality on larvae of rhinoceros beetle (Table 1). The mortality of larvae treated by all types of OrNV increased at slower rate starting from 4 DAT and reached more than $50 \%$ at $20 \mathrm{DAT}$, then peaked at the highest level at 30 DAT. During this period, the OrNV type A inoculum prepared from cell culture recorded the highest mortality, starting from 20 DAT up to 30 DAT. This trend on high mortality on larvae inoculated with OrNV prepared from cell culture was clearly observed again on the OrNV type $\mathrm{C}$ as early as $12 \mathrm{DAT}$, where the treatment CC killed $21.7 \%$, while no mortality was recorded for treatment CG (Table 1). Similar trend was recorded again on the OrNV type C and type A at 16 DAT. Starting from 20 DAT up to 30 DAT, the mortality of larvae treated with all types of OrNV prepared from cell culture was always higher as compared to larval mortality caused by the OrNV from the infected gut tissues. The OrNV type A from cell culture (AC) recorded the highest mortality of $100 \%$, followed by the treatments BC $(88.9 \%), \mathrm{BG}(77.8 \%), \mathrm{CC}(77.8 \%)$, AG $(72.2 \%)$, and CG (61.1\%).

The findings showed that type A of OrNV was capable of killing 100\% larvae at 30 DAT. The result was in agreement with that of Gopal et al. (2001), who found that the infected larvae took less than a month to die. Finding in this study was contrary with the study by Ramle et al. (2011), who found that the highest mortality was caused by the OrNV type

TABLE 1. PERCENTAGE MORTALITY AND INFECTIVITY OF LARVAE AFTER TREATED WITH Oryctes NUDIVIRUS TYPES A, B AND C PREPARED FROM CELL CULTURES AND INFECTED GUT TISSUES USING PERORAL INOCULATION TECHNIQUE

\begin{tabular}{|c|c|c|c|c|c|c|c|c|c|c|}
\hline \multirow[t]{2}{*}{$\begin{array}{l}\text { Type of } \\
\text { OrNV }\end{array}$} & \multirow{2}{*}{$\begin{array}{l}\text { Source of } \\
\text { inoculum } \\
\text { (acronym) }\end{array}$} & \multicolumn{8}{|c|}{$\begin{array}{l}\text { Cumulative mortality }(\%) \text { at day after treatment } \\
\text { (DAT) }\end{array}$} & \multirow{2}{*}{$\begin{array}{c}\text { Total } \\
\text { infectivity } \\
(\%)\end{array}$} \\
\hline & & 4 & 8 & 12 & 16 & 20 & 24 & 28 & 30 & \\
\hline \multirow[t]{2}{*}{ Type A } & Gut tissues (AG) & $6.7 \mathrm{a}$ & $13.3 \mathrm{a}$ & $20.0 \mathrm{a}$ & $38.3 \mathrm{ab}$ & $41.7 \mathrm{~b}$ & $50.0 \mathrm{~b}$ & $69.4 \mathrm{a}$ & $72.2 \mathrm{a}$ & $41.7 \mathrm{a}$ \\
\hline & Cell culture (AC) & $0.0 \mathrm{a}$ & $0.0 \mathrm{a}$ & $12.2 \mathrm{a}$ & $48.9 \mathrm{a}$ & $83.3 \mathrm{a}$ & $91.7 \mathrm{a}$ & $100.0 \mathrm{a}$ & $100.0 \mathrm{a}$ & $13.1 \mathrm{~b}$ \\
\hline \multirow[t]{2}{*}{ Type B } & Gut tissue (BG) & $6.7 \mathrm{a}$ & $13.3 \mathrm{a}$ & $20.0 \mathrm{a}$ & $30.0 \mathrm{ab}$ & $36.1 \mathrm{~b}$ & $47.2 \mathrm{~b}$ & $63.9 \mathrm{a}$ & $77.8 \mathrm{a}$ & $13.1 \mathrm{~b}$ \\
\hline & Cell culture (BC) & $6.7 \mathrm{a}$ & $6.7 \mathrm{a}$ & $13.3 \mathrm{a}$ & $21.7 \mathrm{~b}$ & $44.4 \mathrm{~b}$ & $63.9 \mathrm{ab}$ & $72.2 \mathrm{a}$ & 88.9 a & $13.1 \mathrm{~b}$ \\
\hline \multirow[t]{2}{*}{ Type C } & Gut tissues (CG) & $0.0 \mathrm{a}$ & $0.0 \mathrm{a}$ & $0.0 \mathrm{a}$ & $21.7 \mathrm{~b}$ & $38.9 \mathrm{~b}$ & $47.2 \mathrm{~b}$ & $61.1 \mathrm{a}$ & $61.1 \mathrm{a}$ & $28.1 \mathrm{ab}$ \\
\hline & Cell culture (CC) & $0.0 \mathrm{a}$ & $0.0 \mathrm{a}$ & $21.7 \mathrm{a}$ & $30.0 \mathrm{ab}$ & $44.4 \mathrm{~b}$ & $52.8 \mathrm{~b}$ & $77.8 \mathrm{a}$ & $77.8 \mathrm{a}$ & $35.0 \mathrm{a}$ \\
\hline
\end{tabular}

Note: * Percentage of infectivity was calculated based on cumulative data recorded at 30 DAT.

Means in columns with the same letters were not significant different by Duncan's Multiple Range Test $(\mathrm{DMRT})$ at P $=0.05$. 
B $(86.7 \%)$ followed by type A $(26.7 \%)$ and type C $(13.3 \%)$ on larvae treated with OrNV prepared from infected guts.

Apart from the virus infection, high larval mortality could presumably be due to infection by other microbes such as bacteria and flagellates. Norman et al. (2007) reported that infection by Bacillus thuringiensis and B. popillae had caused mortality to larvae ranging between $25 \%$ to $64 \%$. The infected larvae turned pulpy and became black-brownish or bluish in colour. The infection of Acinetobacter calcoaceticus and flagellum species Monocercomonoides oryctesae and $M$. qadrii on larvae were also reported (Krishnamurthy and Sultana, 1977; Kannan et al., 1980). Another factor contributing to high larval mortality was possibly due to competition from other microorganisms in the gut lumen, as the larval gut content is rich in organic matters and suitable for the growth of microorganisms (Bedford, 2013a).

It was clearly shown in this study that despite of having higher mortality, most of the larvae were dead not due to the OrNV infection (Table 1). The percentages of dead larvae infected with OrNV ranged from $13.1 \%$ and $41.7 \%$. The infectivity of OrNV prepared from different sources of inoculum seems to be inconsistent. Among treatments, the $\mathrm{AC}, \mathrm{BG}$, and $\mathrm{BC}$ have the same and yet the lowest infectivity of $13.1 \%$. The highest infectivity was recorded in treatment $\mathrm{AG}$ at $41.7 \%$, followed by the treatments CC at $35.0 \%$ and CG at $28.1 \%$. Based on the percentage of the total infectivity, the results in this study contradicted to that of Ramle et al. (2011). In this experiment, the type $\mathrm{C}$ prepared from both sources of inoculum had high infectivity on the larvae as compared to the type B in the latter study done by Ramle et al. (2011).

In the natural breeding sites, among the larval instars, the L3 larvae were the most affected by the infection of OrNV (Ramle et al., 2011). The OrNV infection on the third instar larvae ranging from $29 \%$ to $35 \%$, followed by the second instar $(0 \%$ to $25 \%)$ and lastly the first instar larvae $(0 \%$ to $3 \%$ ). This was mainly due to the fact that L3 had the longest lifespan of 112.5 days as compared to the other instars (Bedford, 1980). This explains why it is unavoidable to get samples free from infection, especially larval samples in the control. Although pre-assessment analysis by PCR before the experiment showed that none of the larvae were infected, but some of them get infected $13.3 \%$ at the end of the experiment. This could possibly be due to low numbers of larvae used in the pre-assessment analysis or frequent replacement of new breeding substrates. These substrates could contain OrNV particles as these materials were collected from field and not sterilised.

This also explains the low infectivity rates by OrNV on the larvae. As the larvae used in this study were L3 collected from the plantations, they have been exposed to other microbes from the natural food sources and the environment. The microbial activity within the guts may have interfered with the virus infection in larvae (Ramle et al., 2011; Bedford, 2013a).

No significant difference on total infectivity was recorded between the larvae inoculated with OrNV prepared from infected gut tissues and from cell cultures, except for type A. The infectivity results of all OrNV prepared from cell culture in this study supported the earlier findings by Zelazny et al. (1987) who found that OrNV produced from cell culture could induce high infectivity (Table 1). Thus, these findings could provide an insight that the OrNV produced on cell culture has a potential to be used to control the larvae of rhinoceros beetle in the field, provided that a more economical way to produce the virus is readily available.

\section{Infectivity of OrNV Propagated on Cell Culture on Larvae Tested by Substrate Contamination Inoculation Technique}

In this study, all types of OrNV were produced from two weeks old cell cultures. The larvae were inoculated by substrate contamination technique using large volume of virus inoculum, about 10 $\mathrm{ml}$ per container. As the L3 larvae used in this experiment were about 30 days older than the L3 larvae used in Experiment 1, therefore, in most of the treatments, some of the larvae had turned to prepupae and pupae. These new pupae were proved to be free from OrNV infection by PCR analysis and previous research also stated that none of those pupae collected from the fields were infected by OrNV (Ramle et al., 2011).

The larval mortality was gradually increased starting from between $0.0 \%$ and $6.7 \%$ at four DAT to between $50.0 \%$ and $66.7 \%$ at 30 DAT (Table 2). From four DAT to 28 DAT, the larval mortality treated by OrNV type B was always slightly higher than the other treatments (Table 2). At 30 DAT, OrNV types $\mathrm{B}$ and $\mathrm{C}$ recorded the highest mortality of $66.7 \%$ followed by type A of $50.0 \%$. Based on the total infectivity, the OrNV type $\mathrm{C}$ recorded the highest infection of $15.0 \%$, followed by OrNV types $\mathrm{A}$ and B of only $6.7 \%$. Surprisingly, the high infection of OrNV type $\mathrm{C}$ on larvae in this Experiment 2 was also recorded in Experiment 1, where the type $C$ prepared from cell culture had $35.0 \%$ infection compared to infection by types A and B (13.1\%) (Table 1).

As in Experiment 1, higher mortality and even lower infectivity of OrNV on larvae was again recorded in this experiment. Possible explanations for the high larval mortality have been elaborated in Experiment 1. As expected, the infectivity of OrNV on larvae was even lower as compared to 
TABLE 2. PERCENTAGE MORTALITY AND INFECTIVITY OF LARVAE AFTER TREATED WITH Oryctes NUDIVIRUS TYPES A, B AND C PREPARED FROM CELL CULTURES USING SUBSTRATE CONTAMINATION INOCULATION TECHNIQUE

\begin{tabular}{|c|c|c|c|c|c|c|c|c|c|}
\hline \multirow[t]{2}{*}{ Type of OrNV } & \multicolumn{8}{|c|}{$\begin{array}{l}\text { Corrected cumulative mortality }(\%) \text { at day after treatment } \\
\qquad(\mathrm{DAT})^{*}\end{array}$} & \multirow{2}{*}{$\begin{array}{c}\text { Total } \\
\text { infectivity } \\
(\%)^{*}\end{array}$} \\
\hline & 4 & 8 & 12 & 16 & 20 & 24 & 28 & 30 & \\
\hline Type A & $0.0 \mathrm{a}$ & $0.0 \mathrm{a}$ & $6.7 \mathrm{ab}$ & $15.0 \mathrm{a}$ & $23.3 \mathrm{a}$ & $38.9 \mathrm{a}$ & 50.0 a & $50.0 \mathrm{a}$ & $6.7 \mathrm{a}$ \\
\hline Type B & $6.7 \mathrm{a}$ & $13.3 \mathrm{a}$ & $26.7 \mathrm{a}$ & $35.0 \mathrm{a}$ & $45.0 \mathrm{a}$ & $50.0 \mathrm{a}$ & $66.7 \mathrm{a}$ & $66.7 \mathrm{a}$ & $6.7 \mathrm{a}$ \\
\hline Type C & $0.0 \mathrm{a}$ & $0.0 \mathrm{a}$ & $0.0 \mathrm{~b}$ & $20.0 \mathrm{a}$ & $20.0 \mathrm{a}$ & $25.0 \mathrm{a}$ & $58.3 \mathrm{a}$ & $66.7 \mathrm{a}$ & $15.0 \mathrm{a}$ \\
\hline
\end{tabular}

Note: *Percentage of infectivity was calculated based on cumulative data recorded at 30 DAT.

Means in columns with the same letters were not significant different by Duncan's Multiple Range Test $(\mathrm{DMRT})$ at P $=0.05$.

There were five individuals in each replicates which made up a total of 15 individuals for each treatments including control.

level of infection recorded in Experiment 1. This is because in this experiment, inoculation was made by spreading the OrNV solutions onto breeding substrates, thus exposing the OrNV non-enveloped virion particles to the detrimental abiotic factors. Inactivation of OrNV has been reported due to unfavourable environmental factors such as high temperature, low moisture and microbial activity in breeding materials of the beetles (Wang et al., 2012; Bedford, 2013a). Paulose and Abraham (2002) also found that the OrNV solutions made up from the macerated infected L3 larvae were completely deteriorated after being exposed for more than 4 hr at $37^{\circ} \mathrm{C}$. Bedford (1980) claimed that the virus particles might quickly disintegrate when they were mixed with the larva-rearing substrates. Furthermore, Bedford (2013a) added that a more virulent OrNV would cause rapid death to the insects, thus deteriorated the living host of the virus and resulted in rapid inactivation of the OrNV in the environment.

The evidence of low infectivity of substrate contamination inoculation as compared to peroral inoculation techniques in this study was also reported by other previous researchers. These included reports by Zelazny (1978), Zelazny and Alfiler (1986), and Zelazny et al. (1987), which discovered that the peroral inoculation of OrNV caused much higher infection on the rhinoceros beetle. Jayawardena (2013) has also reported that a significantly higher infection by OrNV was recorded by peroral inoculation as compared to swim inoculation method.

\section{Effects of OrNV Infectivity on Feeding Behaviour of Neonates of Rhinoceros Beetle}

The reduction in food consumption by neonates of rhinoceros beetle inoculated with cells-propagated OrNV types A, B and Cis shown in Figure 1. Although, the food source used in this study was sugar-cane as replacement for the actual food source of the beetle, which is the oil palm tissues, the results can be used to estimate the feeding behaviours of the adults. As early as four DAT, the inoculated neonates fed at almost similar rate with those in control, except for

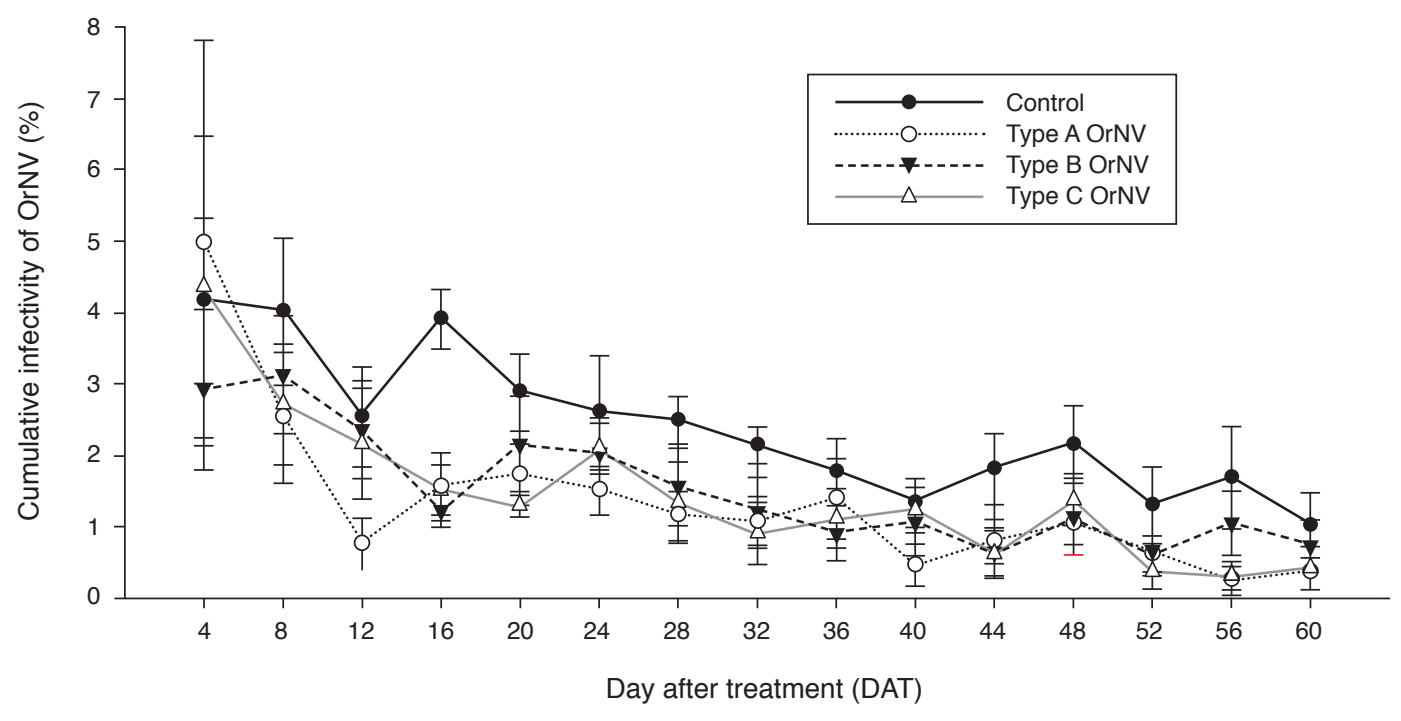

Figure 1. Effects of Oryctes nudivirus (OrNV) types A, B and C in reducing the food consumption by the inoculated neonates of Oryctes rhinoceros. 
neonates treated with the OrNV type B. At this stage, replications of the inoculated virus in the gut tissues have just begun and did not affect the feeding of the neonates. Interestingly, starting from eight DAT to 16 DAT, rapid reduction in food consumption in all treatments was obviously observed, particularly for the OrNV type A. Food consumption by neonates inoculated with the OrNV type A was significantly reduced $(\mathrm{P}<0.05)$ from $3.3 \mathrm{~g}$ at eight DAT to $0.9 \mathrm{~g}$ at 12 DAT. Rapid decrease in food consumption for types B and C was started at 16 DAT from about 3.3 $\mathrm{g}$ to $3.5 \mathrm{~g}$ at eight DAT, then reduced to $1.5 \mathrm{~g}$ at 16 DAT. At 16 DAT onwards, the food consumption by all treated neonates were reduced, but at a more slower rate.

Substantial reduction in food consumption was perhaps due to the massive replication of OrNV in the midgut tissues of the neonates. Extensive replication of OrNV caused the midgut full with the virus particles which substantially disrupted the natural feeding behaviour of the neonates (Huger, 1966; Huger and Krieg, 1991). Inglis et al. (2001) has reported that the impact of OrNV on feeding behaviour of the infected hosts can only be seen between the late stages of infection and before death. This situation was unlikely to happen in the current study. At the early stage between eight DAT to 16 DAT, significant impact of OrNV in reducing the food consumption of neonates was clearly observed. At this period, the PCR analysis on dead neonates found only $5 \%$ to $15 \%$ of them have died due to infection (Figure 2). Even at 20 DAT, the dead neonates with virus infection was still below $20 \%$. It was suspected that the infection level on live inoculated neonates could possibly be much higher. As the experiment ended at $60 \mathrm{DAT}$, the infection of OrNV type B was recorded at $88.0 \%$, type A at $68.0 \%$ and type $\mathrm{C}$ at $56.0 \%$.
The feeding activity by the adults of rhinoceros beetles caused damage to oil palm and reducing yield (Manjeri et al., 2014). The OrNV infection affects the feeding behaviour, as well as the fecundity of the insect hosts as observed in fields by Zelazny (1977). It was obvious that the food consumption in all treatments decreased proportionally with the increased in the infection level by OrNV (Figures 1 and 2). The feeding of the treated neonates decreased over time to below $0.8 \mathrm{~g}$ at 60 DAT and always lower than the amount of food taken by the untreated neonates in the control (Figure 1).

Based on rates of food consumed by neonates in this experiment, it has the same trend of negative exponential curves but with the difference in reduction rates depending on treatments (Figure 3 ). The OrNV Type A has the highest reduction rate of $-0.074 x$, then followed by the type $C$ of $-0.053 x$, type $B$ of $-0.035 x$ and control of $-0.029 x$. From the graphs, it revealed that the reduction on food consumption by neonates was constantly reduced at the slower rate. In actual field conditions, those infected neonates were still capable of causing damage to the palm. Therefore, this explains why infestation of rhinoceros beetle in fields is still occurring despite of high infection of OrNV on adults (Ramle et al., 2011). Low effect of virus infection on feeding activity of the neonates was probably due to the adaptation of the beetle immune system against the OrNV. Zelazny et al. (1989) have reported that the population of rhinoceros beetle in the Philippines has started showing resistance toward OrNV as compared to beetles in West Samoa. Nevertheless, the advantage of slow feeding of the infected beetles is that it increases chances for the beetles in disseminating the virus to other healthy beetles and later reduces the pest populations in the outbreak areas (Zelazny, 1976).

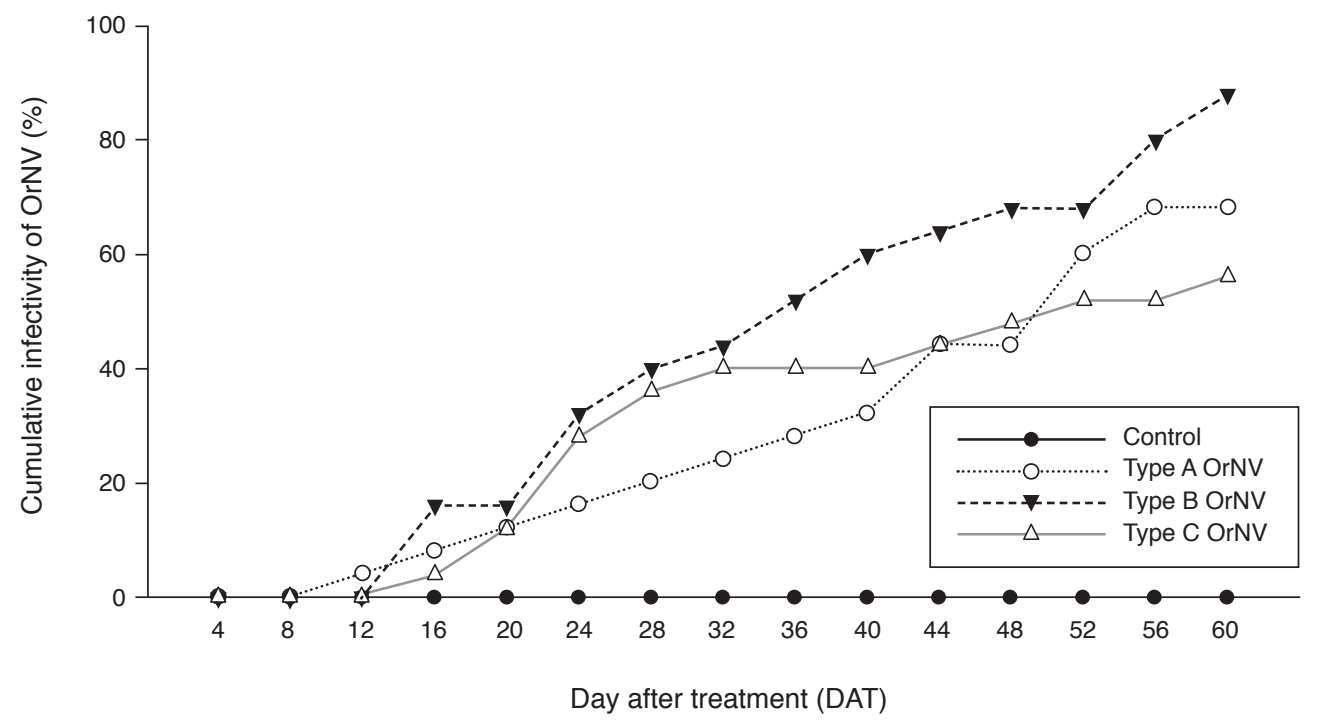

Figure 2. The percentage of cumulative infection of neonates of Oryctes rhinoceros inoculated with Oryctes nudivirus (OrNV) types A, B, and C. 

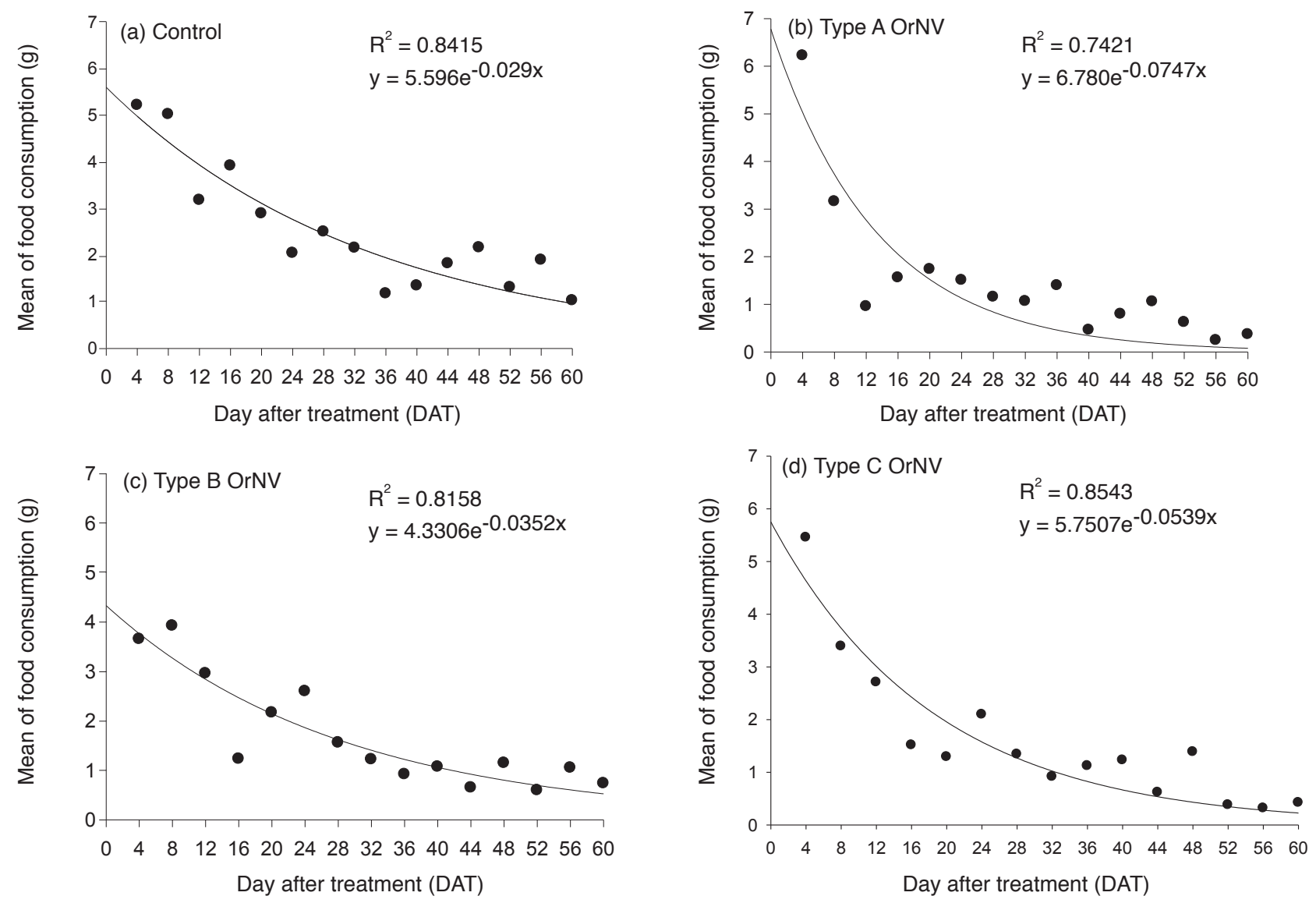

Figure 3. The rate of reduction on food consumption by the neonates of Oryctes rhinoceros after inoculated with the Oryctes nudivirus (OrNV) types $A, B$, and $C$.

\section{CONCLUSION}

In summary, this study found that OrNV prepared from the cell culture has comparatively high infectivity as compared to OrNV freshly prepared from the infected gut tissues. On larvae, the peroral inoculation method caused higher infectivity level ranging from $13.1 \%$ to as high as $41.7 \%$ as compared to food contamination method which caused only between $6.7 \%$ to $15.0 \%$. Based on results in both inoculation methods, the OrNV type $\mathrm{C}$ prepared from cell culture DSIR-HA-1179 was more effective in controlling the L3 larvae than the other types. However, applying OrNV solutions targeting to control larvae in the breeding sites could expose the virus solutions to various detrimental abiotic factors leading to virus inactivation. The inoculation of OrNV has greatly affected the feeding behaviour of the neonates. The effects were obviously showed at the early stage of the experiment between eight DAT to 16 DAT. During this period, the food consumption by all tested OrNV was rapidly reduced and maintained low till the experiment ended at 60 DAT. Based on feeding reduction rates, type A was found to be the most effective in reducing the feeding of neonates, then followed by type $\mathrm{C}$ and type $\mathrm{B}$. This experiment suggested that selection of OrNV for field release not only solely based on the capability of the virus to kill the insect, but also to account the effects of the virus in reducing the feeding of the insect on the plant host.

\section{ACKNOWLEDGEMENT}

The authors would like to express their utmost gratitude to the Director-General of MPOB for permission to publish this article. The authors would also like to thank staff of the Insect Biopesticide Research Group, Applied Entomology and Microbiology Unit of MPOB for helping in conducting the research.

\section{REFERENCES}

ABBOTT, W S (1987). A method of computing the effectiveness of an insecticide. J. American Mosquito Control Association, 3: 302-303.

BEDFORD, G O (1980). Biology, ecology and control of palm rhinoceros beetles. Annual Review of Entomology, 25: 309-339. 
BEDFORD, G O (2013a). Biology and management of palm dynastid beetles: recent advances. Annual Review of Entomology, 58: 353-372.

BEDFORD, G O (2013b). Long term reduction in damage by rhinoceros beetle Oryctes rhinoceros (L.) (Coleoptera: Scarabaeidae: Dynastinae) to coconut palms at Oryctes nudivirus release sites on Viti Levu, Fiji. African J. Agricultural Research, 49: 6422-6425.

CHUNG, G F; CHEAH, S $S$ and BALASUBRAMANIAM, R (1999). Effects of pest damage during immature phase on early yield of oil palm. Proc. of the 1999 PORIM International Palm Oil Congress: Emerging Technologies and Opportunities in the Next Millennium. p. 456-466.

CIK MOHD RIZUAN, Z A; ABU HASSAN, A; HASBER, $S$ and NOOR HISHAM, H (2014). Population dynamics of Oryctes rhinoceros in decomposing oil palm trunks in areas practising zero burning and partial burning. J. Oil Palm Res. Vol. 26: 140-145.

CRAWFORD, A M (1982). A coleopteran cell line derived from Heteronychus arator (Coleoptera: Scarabaeidae). In vitro, 18: 813-816.

CRAWFORD, A M and SHEEHAN, C (1984). An Oryctes rhinoceros baculovirus inoculum derived from tissue culture. J. Economic Entomology, 77: 1610-1611.

CRAWFORD, A M and SHEEHAN, C (1985). Replication of Oryctes baculovirus in cell culture: viral morphogenesis, infectivity and protein synthesis. J. General Virology, 66: 529-539.

FARELL, E M and ALEXANDRE, G (2012). Bovine serum albumin further enhances the effects of organic solvents on increased yield of polymerase chain reaction of GC-rich templates. BMC Research Notes, 5: 257.

FARHAH, R S K N A; WAHIZATUL, A A; NORMAN, K; RAMLAH, A A S and RAMLE, M (2015). Production of Malaysian indigenous Oryctes nudivirus on insect cell line DSIR-HA-1179. Proc. of the PIPOC 2015 International Palm Oil Congress and Exhibition. p. 93-101.

GOPAL, M; GUPTA, A; SATHIAMMA, B and NAIR, C P R (2001). Control of the coconut pest Oryctes rhinoceros L. Using the Oryctes virus. Insect Science and its Application, 21: 93-101.

HUGER, A M (1966). A virus disease of the Indian rhinoceros beetle Oryctes rhinoceros (Linnaeus), caused by a new type of insect virus, Rhabdionvirus oryctes gen. n., sp. n. J. Invertebrate Pathology, 8: 38-51.
HUGER, A M (2005). The Oryctes virus: its detection, identification, and implementation in biological control of the coconut palm rhinoceros beetle, Oryctes rhinoceros (Coleoptera: Scarabaeidae). J. Invertebrate Pathology, 89: 78-84.

HUGER, A M and KRIEG, A (1991). Baculoviridae. Nonoccluded baculoviruses. Atlas of Invertebrate Viruses (Adams, J R and Bonami, J R eds.). CRC Press, Boca Raton. p. 287-319.

INGLIS, G D; GOETTEL, $\mathrm{M}$ S; BUTT, $\mathrm{T} \mathrm{M}$ and STRASSER, H (2001). Use of hypomycetous fungi for managing insect pest. Fungi as Bicontrol Agents: Progress, Problems and Potential (Butt, T M; Jackson, $\mathrm{C}$ and Magan, $\mathrm{N}$ eds.). CABI Publishing, Oxon. p. 23-70.

JAYAWARDENA, S P (2013). Effective inoculation method and optimum concentration of Oryctes virus to infect Oryctes rhinoceros adults. European International J. Science and Technology, 8: 188-194.

KANAN, N; SHANMUGASUNDRAM, $S$ and LAKSHMANAN, M (1980). Isolation of a bacterial pathogen from the coconut pest Oryctes rhinoceros (L.). Entomon, 5: 285-289.

KRISHNAMURTHY, $\mathrm{R}$ and SULTANA, T (1977). Studies on two flagellates of the genus Monocercomonoides Travis 1932 from the gut of dung beetle larve (Oryctes rhinoceros) in India. Archiv fur Protistenkunde, 119: 121-126.

MANJERI, G; MUHAMAD, R and SOON, G T (2014). Oryctes rhinoceros beetles, an oil palm pest in Malaysia. Annual Research \& Review in Biology, 22: 3429-3439.

MARSCHALL, K J (1970). Introduction of a new virus disease of the coconut rhinoceros beetle in Western Samoa. Nature, 225: 288-289.

NORMAN, K (2001). Kajian Persekitaran dan Infestasi Kumbang Badak, Oryctes rhinoceros (Linn.) (Coleoptera: Scarabaeidae) dalam Ekosistem Tanam Semula Sawit. Ph.D. dissertation. Faculty of Science and Technology, Universiti Kebangsaan Malaysia, Bangi, Malaysia. p. 270.

NORMAN, K and BASRI, M W (2004). Immigration and activity of Oryctes rhinoceros within a small oil palm replanting area. J. Oil Palm Res. Vol. 16: 64-77.

NORMAN, K; BASRI, M W; RAMLE, $M$ and RAMLAH, A A S (2007). The effects of mortality and influence of pheromone trapping on the infestation of Oryctes rhinoceros in an oil palm plantation. J. Asia-Pacific Entomology, 10: 239-250. 
PAULOSE, S and ABRAHAM, C C (2002). Effect of constant temperature on the virulence of baculovirus Oryctes (Kerala isolate). J. Entomological Research, 26: 153-156.

RAMLE, M; IDRIS, G; WAHID, M B; GLARE, T $\mathrm{R}$ and JACKSON, T A (2010). Optimization of the polymerase chain reaction (PCR) method for the detection of Oryctes rhinoceros virus. J. Oil Palm Res. Vol. 22: 736-749.

RAMLE, M; NORMAN, K; IDRIS, A G; WAHID, M B; JACKSON, T A; TEY, C C and MOHD AHDLY, A (2011). Molecular approaches in the assessment of Oryctes rhinoceros virus for the control of rhinoceros beetle in oil palm plantations. J. Oil Palm Res. Vol. 23: 1096-1109.

RICHARDS, N K; GLARE, T R; ALOALI'I, I and JACKSON, T A (1999). Primers for the detection of Oryctes virus from Scarabaeidae (Coleoptera). Molecular Ecology, 8: 1552-1553.

SAMSUDIN, A; CHEW, P S and MOHD, M M (1993). Oryctes rhinoceros: breeding and damage on oil palms in an oil palm to oil palm replanting situation. The Planter, 69: 583-591.

SAS SYSTEM (1997). SAS/STAT User's Guide. Volume 1, Version 6.1, SAS Institute Inc., Cary. North Carolina, USA.

WANG, Y; BININDA-EMONDS, O R P and JEHLE, J A (2012). Nudivirus genomics and phylogeny. Viral Genomes - Molecular Structure, Diversity, Gene Expression Mechanisms and Host-virus Interactions (Garcia, M L and Romanowski, V eds.). p. 33-52.

WOOD, B J (1968). Pests of Oil Palm in Malaysia and their Control. Incorporated Society of Planter, Kuala Lumpur.
ZELAZNY, B (1973). Studies on rhabdionvirus oryctes II. Effect on adults of Oryctes rhinoceros. J. Invertebrate Pathology, 22: 122-126.

ZELAZNY, B (1976). Transmissions of baculovirus in population of Oryctes rhinoceros. J. Invertebrate Pathology, 27: 221-227.

ZELAZNY, B (1977). Occurrence of the baculovirus disease of the coconut palm rhinoceros beetle in the Philippines and Indonesia. FAO Plant Protection Bulletin, 25: 73-77.

ZELAZNY, B (1978). Methods for inoculating and diagnosing the baculovirus disease of Oryctes rhinoceros. FAO Plant Protection Bulletin, 26: 163-168.

ZELAZNY, B and ALFILER, A R (1986). Oryctes rhinoceros larvae abundance and mortality factors in the Philippines. Environmental Entomology, 15: 84-87.

ZELAZNY, B and ALFILER, A R (1991). Ecology of baculovirus infected and healthy adults of Oryctes rhinoceros (Coleoptera: Scarabaeidae) on coconut palms in the Philippines. Ecological Entomology, 16: 253-259.

ZELAZNY, B; ALFILER, A R and CRAWFORD, A M (1987). Preparation of a bacculovirus inoculum for use by coconut farmers to control rhinoceros beetle (Oryctes rhinoceros). FAO Plant Protection Bulletin, 35: 37-42.

ZELAZNY, B; ALFILER, A R and LOLONG, A (1989). Possibility of resistance to a baculovirus in populations of the coconut rhinoceros beetles (Oryctes rhinoceros). FAO Plant Protection Bulletin, 37: 77-82. 